\title{
The Impact of Virtual Experience and Informative Control on the Enhancement of Product Understanding
}

\author{
Wu-Yuin Hwang \\ Graduate School of Network \\ Learning Technology, NCU \\ No. 300, Jhongda Rd., Jhongli \\ Taoyuan City 32001, Taiwan
}

\author{
Jung-Lung Hsu \\ Dept. of Information \\ Management, KNU \\ No.1 Kainan Road, Luzhu \\ Taoyuan City 33857, Taiwan
}

\author{
Siao-Han Syu \\ Graduate School of Network \\ Learning Technology, NCU \\ No. 300, Jhongda Rd., Jhongli \\ Taoyuan City 32001, Taiwan
}

\begin{abstract}
There is no doubt that this way of knowledge delivering affords flexible and instant learning. Thus, many instructors afford online material as hypertexts concerning a set of faces and rules for students to generate a basis to achieve a comprehensive understanding. This study borrowed the nature of e-learning and applied its applications to e-commerce to test if the ability of learning by doing is beneficial for users to better understand a product. In this situation, users were treated as learners and they were exposured to in a so-called "situated cognition", which is called virtual experience in ecommerce field. Two laboratory experiments were conducted with 33 participants recruited. The first experiment was to compare the effects of level of interactivity, whereas the last was to compare the effects of affordance of informative control. Our findings indicated that except their perceptions of patronage intention, participants considered no difference in attitude toward the products been demonstrated and shopping enjoyment in a fully 3D-to-3D comparison. However, while providing informative control, participants had higher perceptions of attitude toward the products, shopping enjoyment and patronage intention than their counterparts who had not such support.
\end{abstract}

\section{General Terms}

User interface, Virtual 3D, Online product.

\section{Keywords}

Product presentation, Web3D, Shopping enjoyment, Patronage intention.

\section{INTRODUCTION}

It is widely acknowledged that e-learning is an effective tool in helping both instructors and learners. Because of the benefit of hypertexts, most e-learning systems regard it as a standard representation to provide instructional material. There is no doubt that this way of knowledge delivering affords flexible and instant learning. Thus, many instructors afford amount of hypertext-style material, concerning a set of faces and rules for students to generate a basis to achieve a comprehensive understanding. This popular kind of learning is essentially static in nature since the instructional material is set up by the teachers, and then learners passively receive the content.

However, knowledge construction can be a dynamic process. In this process learners are able to master, retain and generate new knowledge when they are actively involved in knowledge construction through learning by doing. The theoretical basis of this contention is indeed in accordance with the essence of constructivism. The question is if this kind of learning is equally effective in different disciplines such as e-commerce. E-commerce nowadays affords virtual environments for customers to better understand the online products. In this situation, customers are treated as learners and they are exposured to in the so-called "situated cognition" context, which is called virtual experience in e-commerce field.

Moreover, the amount and variety of product information are found to be the key factors that influence the user's understanding toward the products $[1,2,3]$. Nevertheless, in $3 \mathrm{D}$ space, it is not easy to explain 3D products well because of the difficulty of combining detailed illustrations in 3D settings simultaneously. Alternatively, traditional online shopping websites usually demonstrate a product in 3D ways and give further information with 2D symbols (ex. texts and graphics). Hence, users may not completely comprehend the descriptions and specifications while virtually operating the products. Therefore, the objectives of this research are twofold. First, this study was intended to develop a Virtual Products Presentation with Whiteboard system (hereafter VPPW), which equips the user with the ability of learning by doing so that he could manipulate virtual products immediately and read the information relevant to the products at the same time. Second, this study was attempted to investigate the influence of learning by doing on the user's understanding toward the product in a fully 3D-to-3D comparison. Our presumption is that by using VPPW system, users would have better understandings about the products, leading to higher shopping enjoyment and more positive attitude toward the product, and patronage intention, which are three widely accepted concepts in e-commerce filed to indicate one's understanding toward products.

\section{LITERATURE REVIEW 2.1 Interactivity and Product Understanding}

Business, in the past, relied on the ways of direct and indirect experience to impress customers with superior or attractive product features. Although the effects of both of the ways have been documented to significantly affect the consumer's attitude toward the product $[4,5]$, many argue their potential to explain an online customer's attitude toward the goods in a virtual store. For instance, Peterson et al. [6] have argued that "Internet-based marketing would seem to be a poor substitute for traditional transaction channels, where the goods are available for inspection" (p. 335). Seeing the fact, Li et al. [7] conceived virtual experience as an online shopping experience that provides the contexts in which consumers can interact with and try products via technology-supported tools.

Some studies have focused on two types of virtual experience implementation: functional control and visual control. Visual control allows consumers to rotate, zoom in and out, and to move product images with their computers. If some external software, such as flash, is provided, customers can even view the products from different angles. On the contrary, functional control allows customers to see how the product will virtually react in response to the functional mechanism been excited. 
Virtual reality, one of the common techniques to embody virtual experience in 3D settings, can be employed to support both visual and functional control, and then afford customers the way to highly interact with virtual products. In this regard, both visual and functional controls can be seen as attributes of interactivity and the effects of which have indeed been acknowledged. For example, Abend [8] showed that the ability of trying products may be an important interactive feature for apparel web sites because consumers frequently state the inability to try online products. And the interactive nature of web sites also has been acknowledged to positively affect users' responses, including enhancing their interests to browse and purchase online. In addition, after analyzing consumers' online shopping behaviors, Ghose and Dou [9] found that consumers have stronger interests in the products which are presented in interactive websites than the ones displayed in noninteractive websites. The reason is that the navigational process facilitated by interactivity dramatically increased customers' freedom of choice and the level of control experiences [10].

Eckman stated that consumers usually consider virtual products intricate and thereby requires more in-depth examination before purchase [11]. As a result, allowing customers to interact with a remote product may offer detailed indirect however vivid experiences. Another research studying the effects of level of interactive technology found a significant positive effect of interactive technology on user perceptions of online shopping enjoyment $[11,12]$. In fact, $\mathrm{Li}$, et al. [7] found that virtual experience created by 3D environments was much better than indirect experience created by traditional media in facilitating learning. Therefore, it is vital for online stores to consider using 3D technology with high interaction to present virtual products online. Specifically, Li et al found that 3D product presentations outperformed 2D pictorial presentations in enhancing perception of virtual product experience online [13]. Based on those findings, researchers had emphasized on supporting high level of interactivity on virtual $3 \mathrm{D}$ products and facilitate users to manipulate essential functions of $3 \mathrm{D}$ products to simulate real shopping situations. However, participants who have not been exposed to 3D representations of products online may simply be more curious than if the product was presented in 2D format. Thus, it is possible that the previous findings could be conceptualized as byproducts of interacting in a 3D environment. To resolve this notion, a study conducting 3D-to-3D comparisons is suggested.

\subsection{Informative Control}

Apart from visual control and functional control in 3D settings, which may impact consumer perceptions, informative control might affect online shopping. Informative control, in this study, indicates that consumers have their own control over the information been demonstrated. For example, users may read a message associated with the product on the screen, or, on the contrary, they may hide the message anytime when they choose not to see it. This study considers this freedom of informative control as another critical factor mainly because of Uncertainty Reduction Theory URT and Cognitive Load Theory CLT.

According to Uncertainty Reduction Theory (URT), individuals in a highly uncertain situation rely heavily on information exchange and regard it as an input to make a better decision [14]. The tenet of URT is especially remarkable in online shopping settings, where customers are physically distant from the real products and this thereby leads to intensive information asymmetry. Given the lack of direct experience, consumers cannot directly touch and observe the product to justify if it really satisfies their different preferences and demands. On the contrary, customers in online settings receive less information as an input to eliminate unfamiliarity with the product due to the inherent nature of the internet. Information associated with the product, in this point of view, not only helps customers to reduce uncertainty of the product, but has essential influences on their purchase decision. Furthermore, in line with Information Processing Theory (IRT), an individual receives information through his sensory systems and then transforms the message by a variety of mental operations [15]. These operations help the individual constructs needed cognitive processes to understand the object which the input information describes. As a result, both URT and IRT would predict the importance of affording information associated with the products demonstrated in online settings. More specifically, in line with Mayer's contention, a meaningful learning arises as learners work on processing information presented to them, and as they actively construct mental presentations [16]. Given that understanding a product is also a process of learning, this study thereby posits that more information is required for a customer to form the attitude toward the product and to enjoy the shopping experience.

However, after a careful review of the literature, the opposite opinion was found based on the Cognitive Load Theory (CLT). Results from the studies based on this theory consider that the effect of information is not simply a linear function of amount of information. The tenet of CLT is that although capacity of long-term memory is virtually unlimited, one's processing capacity of working memory is actually limited $[15,17]$. Thus, it is obvious that the processing capacity is a mental resource that varies with individuals. If the amount of information does not exceed one's limits, cognitive load probably will not happen in terms of CLT. This study thereby considers that while a consumer is allowed to control information associated with the product, he is more likely to better understand the product because only himself knows how much information is pertinent and when presence of information is timely. However, no empirical research has been conducted to integrate these two theories to achieve a clear understanding about informative control and its effects in 3D shopping settings. Given that the theories have contributed to our understanding of learning a product, it is time to reconcile the seemingly conflicting outcomes regarding informative control in this study.

\section{RESEARCH DESIGN 3.1 Experiment Design}

In this study two laboratory experiments were conducted. Thirty-three undergraduate students were recruited and randomly divided into two groups in order to join different experiments. Based on previous studies, it is considered that interacting with products in 3D settings is a crucial factor in online shopping environment. However, many argue that the effect of the interactivity in 3D settings might be byproducts of interacting in a $3 \mathrm{D}$ environment. Thus, an objective of this study is to investigate whether a user's attitude toward virtual products would vary with different levels of interactivity. Therefore, the first experiment of this study defined two levels of interactivity. In low interactivity setting participants could view a virtual product from different angles, which means they could change perspectives to inspect the product. In this condition, participants had the visual control to see the product in a 3D way. In high interactivity, not only could participants rotate a virtual product in any angle, but they 
were equipped with the power of functional control to interact with the $3 \mathrm{D}$ virtual product and then to see what reaction would appear.

Apart from the comparison of low interactivity and high interactivity in 3D setting, the second experiment investigated the effect of informative control in online shopping environment. In this regard, a comparison of high interactivity without informative control and high interactivity with informative control was conducted. To provide participants with extra informative control, this study created a VPPW system to implement a virtual semi-translucent whiteboards to help users understand products by posting questions or making annotations on it. And whiteboards can be seamlessly integrated on the back of $3 \mathrm{D}$ products and be put in anywhere in the $3 \mathrm{D}$ environment.

\subsection{D Product Presentation Environment}

This study incorporated a semi-translucent multimedia whiteboards into a 3D product presentation system. The 3D products in VPPW system were implemented and employed the open XML-enabled 3D standard which proposed by the Web3D consortium. It integrated multimedia whiteboard into the system. Users can explore products easily without other assistant tools on Internet in VPPW system. With virtual whiteboard, users could represent different signs such as graphics, texts, and annotations to express their ideas and share with others by transferring whiteboard contents. Whiteboard can be put in right position and seamlessly integrated with $3 \mathrm{D}$ products. It could be unfolded to read information and folded to manipulate the products at behind so that users can easily compare the characteristics and functions of products, thereby bringing more convenience and usefulness than traditional advertisements.

Virtual whiteboard is designed for $3 \mathrm{D}$ theme which is a $2 \mathrm{D}$ object and can be created or deleted with flexibility anywhere in 3D space that suit user needs. A high level of interactivity on the 3D virtual product is available for consumers, thus they can explore the essential functions of products and obtain sufficient product information. It also enhances their perception experiences and shopping enjoyment. Furthermore, 3D product presentation system usually only show one product in a time, the VPPW system can put several 3D products together in a 3D space to help consumers to make a contact toward different products conveniently.

Two experiments were conducted in this study. The first purpose was to investigate participants' perceptions while they were exposed in a fully $3 \mathrm{D}$ environment by using VPPW system. The system only allows participants inspect appearance of the $3 \mathrm{D}$ products. After that, in the next experiment, participants had to explore two 3D products again with investigated features, including virtual whiteboard. Each condition lasted about 40 minutes. After each experimental scenario was done, a questionnaire was given to each participant.

\subsection{Samples}

This study first investigated some basic information as to the participants, such as gender, Internet using experience and so on, as shown in Table 1. Notably, students enrolled in the course were mostly female and therefore a high proportion of women were found in this study.
Table 1. Table captions should be placed above the table

\begin{tabular}{|c|c|c|c|}
\hline Variables & Items & Num & $\%$ \\
\hline \multirow{2}{*}{ Gender } & Man & 7 & $21.21 \%$ \\
\hline & Woman & 26 & $78.78 \%$ \\
\hline \multirow{2}{*}{$\begin{array}{l}\text { Internet } \\
\text { using } \\
\text { experience }\end{array}$} & Above three years & 32 & 96.9 \\
\hline & One to three years & 1 & $3.1 \%$ \\
\hline \multirow{3}{*}{$\begin{array}{l}\text { Online } \\
\text { shopping } \\
\text { experience }\end{array}$} & Above five times & 14 & $42.42 \%$ \\
\hline & One to five times & 12 & $36.36 \%$ \\
\hline & Never & 7 & $21.21 \%$ \\
\hline \multirow{2}{*}{$\begin{array}{l}\text { Viewing } \\
\text { 3D virtual } \\
\text { product } \\
\text { experience }\end{array}$} & Yes & 7 & $21.21 \%$ \\
\hline & No & 26 & $79.79 \%$ \\
\hline
\end{tabular}

\section{RESEARCH RESULTS}

\subsection{Interactivity}

There were very few differences with respect to 3D functional support in the dependent sample t-test in Table 2. Participants' perceptions of attitude toward the products, shopping enjoyment and patronage intention were higher in high interactivity group than that in low interactivity group. Based on the value of mean in these groups, participants seem incline to have more positive perceptions on the virtual product as they were equipped with the ability to manipulate it.

However, it also appears in Table 2 that the participant's patronage intentions were significantly different in these two groups. Accordingly, participants in high interactivity had stronger intention to purchase the virtual product, where they could manipulate functions of the product and then evaluate its reactions immediately. Results in this analysis indicate that levels of interactivity would not influence a customer's attitude toward the products and shopping enjoyment. At least, both variables were not statistically significant in this study. Although levels of interactivity may not have impacts on these variables, it does have effects on a customer's patronage intention. Taken together, the finding was consistent with our supposition that findings of previous research might be attributed to a byproduct of interacting in a 3D setting.

Table 2. Comparison results of the interactivity groups

\begin{tabular}{|c|c|c|c|c|}
\hline \multicolumn{2}{|c|}{ Variables } & $\operatorname{Mean}(S . D)$ & $\mathrm{t}$ & Sig. \\
\hline \multirow{2}{*}{ Attitude } & $\begin{array}{l}\text { Low } \\
\text { interactivity }\end{array}$ & $3.22(0.48)$ & \multirow{2}{*}{-1.41} & \multirow{2}{*}{.18} \\
\hline & $\begin{array}{l}\text { High } \\
\text { interactivity }\end{array}$ & $3.41(0.30)$ & & \\
\hline \multirow{2}{*}{ Enjoyment } & $\begin{array}{l}\text { Low } \\
\text { interactivity }\end{array}$ & $3.48(0.45)$ & \multirow{2}{*}{-1.35} & \multirow{2}{*}{.21} \\
\hline & $\begin{array}{l}\text { High } \\
\text { interactivity }\end{array}$ & $3.70(0.18)$ & & \\
\hline \multirow{2}{*}{ Patronage } & $\begin{array}{l}\text { Low } \\
\text { interactivity }\end{array}$ & $3.26(0.51)$ & \multirow{2}{*}{-3.00} & \multirow{2}{*}{$.010^{*}$} \\
\hline & $\begin{array}{l}\text { High } \\
\text { interactivity }\end{array}$ & $3.56(0.44)$ & & \\
\hline
\end{tabular}




\subsection{Information Control}

In next comparison, this study investigated whether equipping participants with the ability to control information relevant to the $3 \mathrm{D}$ products would have any effect on the research variables. Likewise, two kinds of group were formed in this comparison, namely high interactivity without informative control and high interactivity with informative control. Participants in the first group could manipulate the virtual product to see its reactions. On the contrary, participants in high interactivity with informative control group not only could manipulate the virtual product, but they were equipped with the ability to freely control information relevant to the product. As shown in Table 3, participants generally had higher level of perceptions while they could determine when and how to display information. It has been documented in previous analysis that level of interactivity only influences participants' patronage intention. Taken together, it is obvious that the participant had more positive attitude toward the products and felt that the shopping experience was interesting, when they were allowed to control information.

Table 3. Comparison of both groups

\begin{tabular}{|c|c|c|c|c|}
\hline \multicolumn{2}{|c|}{ Variables } & Mean(S.D) & $\mathrm{t}$ & Sig. \\
\hline \multirow[b]{2}{*}{ Attitude } & $\begin{array}{l}\text { High } \\
\text { interactivity }\end{array}$ & $3.14(0.43)$ & \multirow[b]{2}{*}{-4.08} & \multirow[b]{2}{*}{$.001 * *$} \\
\hline & $\begin{array}{l}+ \\
\text { Informative } \\
\text { control }\end{array}$ & $3.64(0.58)$ & & \\
\hline \multirow[b]{2}{*}{ Enjoyment } & $\begin{array}{l}\text { High } \\
\text { interactivity }\end{array}$ & $3.42(0.47)$ & \multirow[b]{2}{*}{-2.63} & \multirow[b]{2}{*}{$.017 *$} \\
\hline & $\begin{array}{l}+ \\
\text { Informative } \\
\text { control }\end{array}$ & $3.74(0.48)$ & & \\
\hline \multirow[b]{2}{*}{ Patronage } & $\begin{array}{l}\text { High } \\
\text { interactivity }\end{array}$ & $3.12(0.54)$ & \multirow[b]{2}{*}{-2.15} & \multirow[b]{2}{*}{$.045^{*}$} \\
\hline & $\begin{array}{l}+ \\
\text { Informative } \\
\text { control }\end{array}$ & $3.44(0.87)$ & & \\
\hline
\end{tabular}

\subsection{Importance of the Constructs}

A positive coefficient was obtained for shopping enjoyment and attitude toward $3 \mathrm{D}$ products $\left(\beta=.592, \mathrm{R}^{2}=.35, \mathrm{t}=\right.$ $3.028, \mathrm{p}<.01)$. The regression analysis results also indicated that both shopping enjoyment $\left(\beta=.516, \mathrm{R}^{2}=.266, \mathrm{t}=2.485\right.$, $\mathrm{p}<.05)$ and attitude toward $3 \mathrm{D}$ products $\left(\beta=.669, \mathrm{R}^{2}\right.$ $=.447, \mathrm{t}=3.710, \mathrm{p}<.01$ ) were significantly related to the participant's patronage intention. Accordingly, participants with more positive attitude toward the $3 \mathrm{D}$ products, and higher perception of shopping enjoyment rated the patronage intention more favorably.

\section{DISCUSSIONS}

Meaning of the results in this study is twofold. First, we corroborated that although the effects of visual and functional control have been documented in prior research, findings of the studies might be questionable. After combining the findings of this study and prior research, this study found that research documenting the effectiveness of visual and functional control might have misguided academics and practitioners in this domain. Strictly speaking, this is not the first research documenting that the effect of 3D visualization may distort findings of previous studies that researchers found. In fact, $\mathrm{Li}$ et al. showed that users had more positive responses when they were exposed to $3 \mathrm{D}$ visualizations if compared to 2D graphics of the product [18]. Thus, it should be applied with care, that virtual experience has the potential to improve consumer product knowledge and attitudes toward brands $[2,19,20]$. Therefore, future research should take into account the side effects result from comparisons of 3D and 2D visualization, and then replicate the study to examine the clear effect of virtual experience.

Another meaning of the result is that participant's patronage intention was exactly influenced by functional control. Unlike in the low interactivity setting, which solely supported visual control, users in the high interactivity scenario could arbitrarily interact with the product being introduced, leading them to being more inclined to revisit the site. In this regard, functional control serves as the oil, which lubricates the process of choosing an online site, rather than as a product simulator. Based on the finding, it is conceptualized that virtual experience might have impacted on, at least, three dimensions, namely attitude toward learning sites, attitude toward learning process, and attitude toward objects being interacted. In this study, we found visual control has no any effect on one of the three dimensions whereas functional control has influences on attitude toward learning sites. Reason behind this finding might be that since users are physically distant from the real products, they need a way to evaluate if responses of the product are reasonable and acceptable while selecting an online site for them to better understand a product.

As to the second question, in our research design, participants in high interactivity condition with freedom of informative control could post messages on the 3D virtual space nearby the product. It was ascertained in the first experiment that functional control had no effects on the user's attitude toward products and shopping enjoyment. However, this study found that an individual's attitude toward products and shopping enjoyment were significantly affected when combining visual and functional control together with informative control.

The explanation is that both bidirectional information exchange and instant feedback are acknowledged to be the critical features of online environment $[21,22,23]$. While users are used to work out a product's quality based on interacting with it directly, they may consider that online information relevant to the products is insufficient and less acceptable. This is not the first study having this suspect. In fact, Rose and her colleagues also concluded that the insufficient presentation richness of online product demonstrations is a major impediment to e-commerce [24]. In other words, the inherent limitation of the Internet to afford rich product information makes the consumer less knowledgeable about the product of interest to him, which in turn decreases his intention to make a purchase [1]. Similarly, Ducoffe conducted a study examining the relationships among attitude, emotion, and cognition [25]. His finding has documented that the user's cognition would affect their attitude toward webpage advertisement. However, offering users as much information as we can does not guarantee a better understanding of the products because our capacity to process information is a limited resource and is constrained by individual difference. Informative control thus serves as a complementary solution allowing users to determine a pertinent amount of information in their willingness. 


\section{CONCLUSIONS}

In e-learning environment students are active learners, and their ability of learning by doing virtually influences their learning outcomes. This study was intended to shed light on how to make use of this ability in a business course such as ecommerce. The ability of learning by doing virtually in ecommerce field was conceptualized into two dimensions of interactivity, namely visual and functional control. Furthermore, the user's attitude toward the products, shopping enjoyment and patronage intention were regarded as indicators representing the extent of the product understanding. This study also interested in whether affording informative control would have impacts on one of the users' perceptions been studied in this research. Results of the analysis show that perceived attitude toward products, shopping enjoyment and patronage intention were all positively related to the affordance of informative control in the experiment.

Inherent in studies are the limitations that may distort the validity and reliability of the results. In this regard, a couple of limitations should be taken into account while explaining the findings. First, this study recruited students as the sample along with conducting laboratory experiments. This kind of experiment has limited generalizability and thereby should be careful in its applicability. Second, results of this study excluded numerous products for examining the effects of each of the variables. Therefore, findings of this study may not completely be generalizable to all products. However, to best of our knowledge, this is the first paper in e-commerce research that attempts to conceptualize the unexplored area of 3 -D visualization in online shopping. Furthermore, the sample is biased (7 men, 26 women) especially when the research topic is relevant to aesthetics, which might be interfered by participant gender [26,27].

Finally, further research replicating and extending in this area are encouraged to validate and confirm the findings and to fully comprehend the influence of virtual product experiences. Further studies exploring the effect of informative control on product choice and satisfaction could result in significant findings. Consumers' characteristics are needed to test if different styles of information processing would affect their purchasing decisions. In addition, research investigating the effects of mental imagery and the perception of telepresence may offer significant findings for enhancing our comprehension of the psychological impact of compelling virtual experiences created by affording visual, functional and informative control.

\section{REFERENCES}

[1] Hall, R. H., and Hanna P. 2004. The impact of web page text-background colour combinations on readability, retention, aesthetics and behavioural intention. Behaviour \& Information Technology, 23(3), 183-195.

[2] Sauer, J., and Sonderegger A. 2010. The influence of product aesthetics and user state in usability testing. Behaviour \& Information Technology, 30(6), 787-796.

[3] Palmer, J. W. 2002. Web site usability, design, and performance metrics. Information Systems Research, 13(2), 151-167.

[4] Hoch, S. J., and Deighton, J. 1989. Managing what consumers learn from experience. The Journal of Marketing, 53, 1-20.
[5] Kempf, D. A. S., and Smith, R. E. 1998. Consumer processing of product trial and the influence of prior advertising: A structural modeling approach. Journal of Marketing Research, 35(3), 325-338.

[6] Peterson, R. A., Balasubramanian, S., and Bronnenberg, B. J. 1997. Exploring the implications of the internet for consumer marketing. Journal of the Academy of Marketing Science, 25(4), 329-346.

[7] Li, H., Daugherty, T., and Biocca, F. 2001 Characteristics of virtual experience in electronic commerce: A protocol analysis. Journal of Interactive Marketing, 15(3), 13-30.

[8] Abend, J. 2001. Tapping into a virtual world. Bobbin, 42(6), 38-47.

[9] Ghose, S., and Dou, W. 1998. Interactive Functions and Their Impacts on the Appeal of Internet Presence Sites, Journal of Advertising Research, 38(2), 29-43.

[10] Hoffman, D. L., and Novak, T. P. 1996. Marketing in hypermedia computer-mediated environments: Conceptual foundations. The Journal of Marketing, 60(3), 50-68.

[11] Ekman, P. (Ed.). 2006. Darwin and facial expression: A century of research in review. Ishk.

[12] Song, G., and Salvendy G. 2003. A framework for reuse of user experience in Web browsing. Behaviour \& Information Technology, 22(2), 79-90.

[13] Li, H., Daugherty, T., and Biocca, F. 2003. The role of virtual experience in consumer learning. Journal of Consumer Psychology, 13(4), 395-407.

[14] Berger, C. R., and Calabrese, R. J. 1975. Some explorations in initial interaction and beyond: Toward a developmental theory of interpersonal communication. Human Communication Research, 1(2), 99-112.

[15] Miller, G. A. 1956. The magical number seven, plus or minus two: Some limits on our capacity for processing information. Psychological Review, 63(2), 81-97.

[16] Mayer, R. E. 2003. The promise of multimedia learning: Using the same instructional design methods across different media. Learning and Instruction, 13(2), 125139.

[17] Chi, M. T. H., Glaser, R., and Rees, E. 1982. Expertise in problem solving, In R. J. Sternberg (Eds.), Advances in the psychology of human intelligence, Volume 1, Hillsdale, NJ: Erlbaum.

[18] Li, H., Daugherty, and T., Biocca, F. 2002. Impact of 3$\mathrm{D}$ advertising on product knowledge, brand attitude, and purchase intention: The mediating role of presence. Journal of Advertising, 31(3), 43-57.

[19] Schenkman, B. N., and Jönsson F. U. 2000. Aesthetics and preferences of web pages. Behaviour \& Information Technology, 19(5), 367-77.

[20] Raney, A. A., Arpan, L. M., Pashupati, K., and Brill, D. A. 2003. At the movies, on the web: An investigation of the effects of entertaining and interactive web content on site and brand evaluation. Journal of Interactive Marketing, 17(4), 38-53. 
[21] Jiang, Z., and Benbasat, I. 2007. Investigating the influence of the functional mechanisms of online product presentations. Information Systems Research, 18(4), 454470 .

[22] Hegh, R. T. 2008. Case study: integrating usability activities in a software development process. Behaviour \& Information Technology, 27(4), 301-306.

[23] Oldenburger, K., Lehto X., Feinberg R., Lehto M., and Salvendy G. 2008. Critical purchasing incidents in ebusiness. Behaviour \& Information Technology, 27(1), 63-77.

[24] Rose, G., Khoo, H., and Straub, D. W. 1999. Current technological impediments to business-toconsumer electronic commerce. Communications of the AIS, 1, 16.
[25] Ducoffe, R. H. 1996. Advertising value and advertising on the web. Journal of Advertising Research, 36(5), 2132.

[26] Moss, G. A., and Gunn R. W. 2009. Gender differences in website production and preference aesthetics: preliminary implications for ICT in education and beyond. Behaviour \& Information Technology, 28(5), 447-460.

[27] Tzou, R. C., and Lu H. P. 2009. Exploring the emotional, aesthetic, and ergonomic facets of innovative product on fashion technology acceptance model. Behaviour \& Information Technology, 28(4), 311-322. 